\title{
A workplace stretching program for the prevention of musculoskeletal disorders in perioperative staff: A mixed methods implementation study
}

Follow this and additional works at: https://www.journal.acorn.org.au/jpn

(c) (i)

This work is licensed under a Creative Commons Attribution 4.0 License.

\section{Recommended Citation}

King, Alison; Campbell, Joanne; James, Carole; and Duff, Jed (2020) "A workplace stretching program for the prevention of musculoskeletal disorders in perioperative staff: A mixed methods implementation study," Journal of Perioperative Nursing: Vol. 33 : Iss. 4 , Article 1.

Available at: https://doi.org/10.26550/2209-1092.1100

https://www.journal.acorn.org.au/jpn/vol33/iss4/1

This Article is brought to you for free and open access by Journal of Perioperative Nursing. It has been accepted for inclusion in Journal of Perioperative Nursing by an authorized editor of Journal of Perioperative Nursing. 


\section{Authors}

Alison King

BN, RN

Perioperative Department, Port Macquarie

Base Hospital

Joanne Campbell

BN, RN

Nurse Manager, Perioperative Department,

Port Macquarie Base Hospital

Associate Prof Carole James

PhD

Associate Professor, School of Health Sciences, University of Newcastle

Prof Jed Duff

PhD, RN, FACORN

Professor, School of Nursing, Faculty

of Health, Queensland University of

Technology Nursing and Midwifery

Research Centre, Royal Brisbane and

Women's Hospital

\section{Corresponding author}

Alison King

BN, RN

Registered Nurse, Perioperative Department, Port Macquarie Base

Hospital

Alison.king1@health.nsw.gov.au

\title{
A workplace stretching program for the prevention of musculoskeletal disorders in perioperative staff: A mixed- methods implementation study
}

\author{
Abstract \\ Aim: The study aimed to investigate the acceptability, feasibility, use and \\ impact of a workplace stretching program for preventing musculoskeletal \\ disorders in perioperative staff.
}

Method: This was a hybrid effectiveness-implementation study using mixed methods. Data was collected pre- and post-program to evaluate its impact on musculoskeletal disorders, discomfort, sick leave, incidents and compensation claims. A post-program survey and participant interviews were used to ascertain the programs acceptability, feasibility and use.

Results: A total of 42 staff participated in the study. Following the program, there was a 60 per cent reduction in the odds of a musculoskeletal-related incident (OR $0.4,95 \% \mathrm{Cl} 0.1,8.0 p=0.01)$ when compared with the rest of the hospital. The odds of a workers compensation claim reduced by 50 per cent (OR $0.5,95 \% \mathrm{Cl} 0.1,1.5, \mathrm{p}=0.8$ ) and there was a 20 per cent decrease in the odds of a musculoskeletal disorder (OR $0.8,95 \% \mathrm{Cl} 0.1,7.0, \mathrm{p}=0.8$ ) or sick leave (OR $0.8,95 \% \mathrm{Cl} 0.1,6.1, \mathrm{p}=0.8$ ). There was no significant change in musculoskeletal discomfort scores pre- and post-program $(+0.2,95 \% \mathrm{Cl}-7.0$, $7.3, p=0.9$ ). Greater than 70 per cent of participants felt that the program was acceptable and feasible with over 85 per cent agreeing that it was a good fit and matched department needs. Interviews with participants identified positive physical, psychological and cultural benefits. The most common shortcoming reported by staff was not having the opportunity to use the program enough.

Conclusion: Given the positive results and the fact that the program requires minimal resources, it is recommended that other perioperative departments consider implementing a similar program to complement existing work health and safety initiatives.

\section{Background}

A musculoskeletal disorder means an injury to, or disease of, the musculoskeletal system, whether occurring suddenly or over time. It encompasses a range of conditions that affect bones, joints, muscles, tendons and soft tissues 1 . Workrelated musculoskeletal disorders have been identified as a priority disorder by Safe Work Australia?
Work-related injuries cost Australian workers, employers and the community \$62 billion annually, with 51 per cent of these costs attributable to musculoskeletal disorders'. The health care industry has the highest number of work-related injuries and illnesses when compared to other industries².

Musculoskeletal disorders are particularly common in staff working 
in the perioperative environment because of the nature of the work and tasks performed. These tasks involve patient handling, prolonged standing and wearing lead protective aprons. Work injuries commonly reported in this group of workers relate predominantly to the back, neck, shoulder, leg or foot ${ }^{3}$.

Workplace stretching can facilitate a reduction in musculoskeletal stress and strain from awkward postures and static loading. Benefits of stretching include improved flexibility, range of motion, circulation, posture and stress relief ${ }^{4}$. Workplace stretching has been shown to reduce musculoskeletal discomfort and injury in office workers, factory workers and firefighters ${ }^{5}$. There has been recent evidence of the benefit of workplace stretching programs for surgeons ${ }^{6-8}$ but not for other perioperative staff.

\section{Aim}

This study aimed to:

1. evaluate the impact of a workplace stretching program for perioperative staff on musculoskeletal disorders, incidents, workers compensation claims, sick leave and discomfort scores

2. describe the program's acceptability, feasibility and use from the perspective of participants.

\section{Method}

\section{Design}

This was a hybrid effectivenessimplementation study using mixed methods. The benefit of this type of design is the greater understanding of the implementation of the program, which enables more rapid translation of findings to practice? Data was collected pre- and post- program to evaluate its impact on musculoskeletal disorders, discomfort, sick leave, incidents and compensation claims. A postprogram survey and interviews were used to ascertain the programs acceptability, feasibility and use. The study ran from April 2019 to October 2019. It was approved by the University of Newcastle Human Research Ethics Committee (H-20180456) and North Coast NSW Human Research Ethics Committee (LNR/19/ NCC/20).

\section{Setting and participants}

The study was conducted in the perioperative department of a regional base hospital in NSW Australia. The facility has eight theatres and approximately 85 perioperative staff. Staff were eligible to participate if they worked at least two days per week. Eligible staff were sent an email inviting them to participate in the study. The email included details of the research and what was required for participation. Interested staff completed a consent form and baseline survey before being oriented to the program. People with pre-existing musculoskeletal injuries were required to seek approval from their treating health professional before participation.

\section{Workplace stretching program}

The design of the program was based on stretching programs that had been proven to be effective in other workplace settings $\mathrm{s}^{10,11}$. The stretching station was located in an unused bay of the recovery unit close to all working areas. Participants were orientated to the stretching station by the first author under the guidance of the study physiotherapist. The orientation included a briefing on the equipment (stability ball, foam roller, mat), the stretches and emergency procedures. Instructions for each stretch were displayed on posters located on the walls of the stretching station. Participants were instructed to undertake ten minutes of stretching two or three times per week during breaks, or immediately before or after work.

\section{Outcomes and data collection}

Musculoskeletal disorders, discomfort and sick leave data was collected from participants in pre- and post-program surveys. The validated Cornell Musculoskeletal Discomfort Questionnaire (CMDQ) was used to measure discomfort ${ }^{12}$. The instrument asks how often in the last week participants experienced pain, aches or discomfort in twelve different body parts (frequency score), how uncomfortable it was (discomfort score), and whether it interfered with their ability to work (interference score). Data about musculoskeletal-related incidents and workers compensation claims was collected from administrative records for the study period and the corresponding period of the previous year. An incident was defined as any event that exposed a person to a serious risk to health or safety?. Acceptability, feasibility and use were assessed in the post-program survey, using questions from a previously validated tool ${ }^{13}$. They were further explored in the follow-up interviews with consenting participants. The interviews were completed at a mutually convenient time and audio recorded to allow analysis.

\section{Data analysis}

Baseline characteristics, demographics, acceptability, feasibility and use were reported descriptively using frequencies and percentages or means and standard deviations. Mixed-effects linear or simple regression were used 
to examine the relationship between musculoskeletal disorders, discomfort, sick leave, incidents and compensation claims pre- and post-program. Results were presented as odds ratios (ORs) with an OR less than one representing a reduction in the likelihood of an outcome. Interviews with participants were audio-recorded and transcribed verbatim. Thematic analysis was conducted by the first and fourth author using an approach described by Braun and Clarke ${ }^{14}$. The steps included becoming familiar with the data, generating initial codes and then collating data according to those codes, searching for and reviewing themes, defining and naming the themes, and producing a report.

\section{Results}

\section{Demographics and baseline characteristics}

A total of 42 of 85 staff participated in the program. Table 1 describes the demographic characteristics of the participants. The majority were female $(67 \%)$ and working full-time (74\%) in a nursing position (57\%). Five (12\%) junior medical staff described their role as other. The average age of participants was 43 years and their self-reported health status was excellent (60\%) or good (38\%). Twenty-one per cent of participants reported a pre-existing musculoskeletal disorder including osteoarthritis, arthritis, bursitis, tendinitis, plantar fasciitis, sprain and muscle strain.

Table 2 shows the approximate time participants spend performing highrisk tasks (tasks associated with musculoskeletal injury). Ten of the 13 tasks were performed relatively infrequently. The three tasks with the highest exposure were sitting, pushing or pulling objects, and standing static in one place.

Table 1: Participant demographics $(n=42)$

\begin{tabular}{|c|c|c|}
\hline \multicolumn{2}{|l|}{ Demographics } & $\begin{array}{c}\text { Mean (SD) } \\
\text { or } n(\%)\end{array}$ \\
\hline \multicolumn{2}{|l|}{ Age (years) } & $43(10)$ \\
\hline \multirow[t]{2}{*}{ Gender } & Female & $28(67 \%)$ \\
\hline & Male & $14(33 \%)$ \\
\hline \multicolumn{2}{|l|}{ Weight (kg) } & $77(14)$ \\
\hline \multicolumn{2}{|l|}{ Height $(\mathrm{m})$} & $171(10)$ \\
\hline \multirow[t]{3}{*}{ Health status } & Excellent / very good & $25(60 \%)$ \\
\hline & Good/fair & $16(38 \%)$ \\
\hline & Poor & $1(2.4 \%)$ \\
\hline \multicolumn{2}{|c|}{ Existing musculoskeletal disorder } & $9(21 \%)$ \\
\hline \multirow[t]{2}{*}{ Experience (years) } & Current position & $9(9 \%)$ \\
\hline & Total career & $13(9 \%)$ \\
\hline \multicolumn{2}{|c|}{ Work hours per week } & $39(8)$ \\
\hline \multirow[t]{8}{*}{ Role } & Nurse (instrument/circulating) & $12(29 \%)$ \\
\hline & Nurse (anaesthetics) & $5(12 \%)$ \\
\hline & Nurse (recovery) & $4(9.5 \%)$ \\
\hline & Nurse (mixed) & $3(7.2 \%)$ \\
\hline & Operational assistant & $4(9.5 \%)$ \\
\hline & Anaesthetist & $5(12 \%)$ \\
\hline & Surgeon & $4(9.5 \%)$ \\
\hline & Other & $5(12 \%)$ \\
\hline \multirow[t]{3}{*}{ Status } & Full-time & $31(74 \%)$ \\
\hline & Part-time & $11(26 \%)$ \\
\hline & Casual & 0 \\
\hline
\end{tabular}

\section{Musculoskeletal discomfort scores}

The discomfort score for each body part was calculated by summation of the frequency, discomfort and interference scores. The total musculoskeletal discomfort score was calculated by summation of the scores of all body parts. Table 3 reports the post-program change with 95 per cent confidence intervals for the total body score. There was a non-significant +0.2 (95\% Cl -7.0, $7.3, p=0.9$ ) increase in the total musculoskeletal score post-program.

\section{Musculoskeletal disorders and sick leave}

Table 4 shows the self-reported musculoskeletal disorders and sick leave pre- and post-program. Following the program, the odds of a work-related musculoskeletal disorder were reduced by 20 per cent (OR 0.8, 95\% Cl 0.1, 7.0, p = 0.8) as were the odds of musculoskeletalrelated sick leave (OR $0.8,95 \% \mathrm{Cl}$ $0.1,6.1, p=0.8)$. The confidence intervals for these outcomes are wide and overlap, indicating it is not statistically significant. 
Table 2: Approximate percentage of time spent performing high-risk tasks

\begin{tabular}{|c|c|c|c|c|c|c|}
\hline \multirow[b]{2}{*}{ Tasks } & \multicolumn{6}{|c|}{$\begin{array}{l}\text { Approximate percentage of time spent performing tasks } \\
\mathbf{n}(\%)(\text { The highest percentage score is highlighted.) }\end{array}$} \\
\hline & $0 \%$ & $10 \%$ & $25 \%$ & $50 \%$ & $75 \%$ & $100 \%$ \\
\hline $\begin{array}{l}\text { Handling bulky objects } \\
\text { at arm's length }\end{array}$ & $9(21 \%)$ & $15(36 \%)$ & $4(9.5 \%)$ & $8(19 \%)$ & $6(14 \%)$ & 0 \\
\hline $\begin{array}{l}\text { Carrying > } 5 \text { kg with } \\
\text { one hand }\end{array}$ & $14(33 \%)$ & $11(26 \%)$ & $8(19 \%)$ & $7(17 \%)$ & $2(4.8 \%)$ & 0 \\
\hline $\begin{array}{l}\text { Handling difficult to } \\
\text { grip objects }\end{array}$ & $11(26 \%)$ & $15(36 \%)$ & $7(17 \%)$ & $3(7.1 \%)$ & $4(9.5 \%)$ & 0 \\
\hline $\begin{array}{l}\text { Pushing/pulling } \\
\text { objects (carts, tables) }\end{array}$ & $2(4.8 \%)$ & $14(33 \%)$ & $9(21 \%)$ & $7(17 \%)$ & $6(14 \%)$ & $4(9.5 \%)$ \\
\hline Carrying $5 \mathrm{~kg}$ to $15 \mathrm{~kg}$ & $8(19 \%)$ & $14(33 \%)$ & $7(17 \%)$ & $8(19 \%)$ & $3(7.1 \%)$ & 0 \\
\hline Carrying > 15 kg & $18(43 \%)$ & $13(31 \%)$ & $5(12 \%)$ & $3(7.1 \%)$ & $1(2.4 \%)$ & 0 \\
\hline $\begin{array}{l}\text { Carrying }>5 \mathrm{~kg} \text { for } \\
\text { more than } 12 \mathrm{~m}\end{array}$ & $21(50 \%)$ & $13(31 \%)$ & $4(9.5 \%)$ & $2(4.8 \%)$ & $2(4.8 \%)$ & 0 \\
\hline Sitting & $8(19 \%)$ & $10(24 \%)$ & $15(36 \%)$ & $5(12 \%)$ & $2(4.8 \%)$ & $2(4.8 \%)$ \\
\hline $\begin{array}{l}\text { Standing static in one } \\
\text { place }\end{array}$ & $4(9.5 \%)$ & $6(14 \%)$ & $9(21 \%)$ & $16(38 \%)$ & $3(7.1 \%)$ & $4(9.5 \%)$ \\
\hline Kneeling or squatting & $18(43 \%)$ & $17(40 \%)$ & $5(12 \%)$ & 0 & 0 & $2(4.8 \%)$ \\
\hline $\begin{array}{l}\text { Working on elevated } \\
\text { surfaces }\end{array}$ & $30(71 \%)$ & $6(14 \%)$ & $2(4.8 \%)$ & $2(4.8 \%)$ & $1(2.4 \%)$ & $1(2.4 \%)$ \\
\hline $\begin{array}{l}\text { Working on slippery/ } \\
\text { uneven surfaces }\end{array}$ & $24(57 \%)$ & $7(17 \%)$ & $6(14 \%)$ & $4(9.5 \%)$ & 0 & $1(2.4 \%)$ \\
\hline Wearing lead aprons & $13(31 \%)$ & $11(26 \%)$ & 8 (19\%) & $6(14 \%)$ & $2(4.8 \%)$ & $2(4.8 \%)$ \\
\hline
\end{tabular}

Table 3: Change in musculoskeletal discomfort scores pre- and post-program

\begin{tabular}{|c|c|c|c|c|}
\hline $\begin{array}{l}\text { Musculoskeletal } \\
\text { discomfort }\end{array}$ & $\begin{array}{c}\text { Pre-program }(n=42) \\
\text { mean }(95 \% \mathrm{Cl})\end{array}$ & $\begin{array}{c}\text { Post-program }(n=29) \\
\text { mean }(95 \% \mathrm{Cl})\end{array}$ & Change $(95 \% \mathrm{Cl})$ & p-value \\
\hline Total body score & $20.4(15.0,25.9)$ & $20.6(14.3,27.0)$ & $+0.2(-7.0,7.3)$ & 0.9 \\
\hline
\end{tabular}

Table 4: Self-reported musculoskeletal disorders (MSD) and sick leave pre- and post-program

\begin{tabular}{|l|c|c|c|}
\hline Outcome & $\begin{array}{c}\text { Pre-program } \\
\mathrm{n} / \text { total (\%) }\end{array}$ & $\begin{array}{c}\text { Post-program } \\
\mathrm{n} / \text { total (\%) }\end{array}$ & OR (95\% CI) \\
\hline $\begin{array}{l}\text { Work-related MSD in } \\
\text { past six months }\end{array}$ & $4 / 41(9.8 \%)$ & $2 / 23(8.7 \%)$ & $0.8(0.1,7.0)$ \\
\hline $\begin{array}{l}\text { Sick leave for MSD } \\
\text { in past six months }\end{array}$ & $4 / 41(9.8 \%)$ & $2 / 23(8.7 \%)$ & $0.8(0.1,6.1)$ \\
\hline
\end{tabular}


Table 5: Musculoskeletal-related incidents and compensation claims pre- and post-program compared to the rest of the hospital

\begin{tabular}{|l|l|c|c|c|c|}
\multirow{2}{*}{ Outcome } & Department & $\begin{array}{c}\text { Pre-program } \\
\text { n/total (\%) }\end{array}$ & $\begin{array}{c}\text { Post-program } \\
\text { n/total (\%) }\end{array}$ & $\begin{array}{c}\text { Pre-program } \\
\text { OR (95\% CI) }\end{array}$ & $\begin{array}{c}\text { Post-program } \\
\text { OR (95\% CI) }\end{array}$ \\
\hline \multirow{2}{*}{ Incident } & Perioperative & $8 / 89(8.9 \%)$ & $3 / 85(3.5 \%)$ & $4.1(1.6,10.7)$ & $0.4(0.1,8.0)$ \\
\cline { 2 - 6 } & Rest of hospital & $73 / 837(8.7 \%)$ & $62 / 848(7.3 \%)$ & Ref & $0.6(0.3,1.5)$ \\
\hline \multirow{2}{*}{ Claim } & Perioperative & $6 / 89(6.7 \%)$ & $0 / 85(0 \%)$ & $1.1(0.5,2.3)$ & $0.5(0.1,1.5)$ \\
\cline { 2 - 6 } & Rest of hospital & $15 / 837(1.7 \%)$ & $10 / 848(1.1 \%)$ & Ref & $0.8(0.6,1.2)$ \\
\hline
\end{tabular}

Table 6: Acceptability, feasibility and program use

\begin{tabular}{|c|c|c|c|c|c|}
\hline \multirow[b]{2}{*}{ Acceptability and feasibility } & \multicolumn{5}{|c|}{$\begin{array}{l}\text { Agreement } \\
\text { (The highest percentage score is highlighted.) }\end{array}$} \\
\hline & $\begin{array}{l}\text { Strongly } \\
\text { agree }\end{array}$ & Agree & Neither & Disagree & $\begin{array}{l}\text { Strongly } \\
\text { disagree }\end{array}$ \\
\hline I will continue to use the program & $11(39 \%)$ & $7(25 \%)$ & $9(32 \%)$ & $1(3.6 \%)$ & 0 \\
\hline The program was beneficial for me & $10(36 \%)$ & $10(36 \%)$ & $6(21 \%)$ & $1(3.6 \%)$ & 0 \\
\hline $\begin{array}{l}\text { The program is a good fit for our } \\
\text { workplace }\end{array}$ & $12(43 \%)$ & $13(46 \%)$ & $2(7.1 \%)$ & $1(3.6 \%)$ & 0 \\
\hline $\begin{array}{l}\text { The program is a good match for } \\
\text { our needs }\end{array}$ & $13(46 \%)$ & $14(50 \%)$ & 0 & $1(3.6 \%)$ & 0 \\
\hline The program was easy to use & $11(39 \%)$ & $8(29 \%)$ & $4(14 \%)$ & $4(14 \%)$ & $1(3.6 \%)$ \\
\hline $\begin{array}{l}\text { The program seemed easy to } \\
\text { implement }\end{array}$ & $10(36 \%)$ & $8(29 \%)$ & $7(25 \%)$ & $2(7.1 \%)$ & $1(3.6 \%)$ \\
\hline Anticipated vs actual use & $1 /$ day & 3/week & 1/week & $1 /$ month & Never \\
\hline I aimed to use the program & $10(35 \%)$ & $13(46 \%)$ & $3(10 \%)$ & $2(7 \%)$ & 0 \\
\hline I used the program & 0 & $5(17 \%)$ & $7(25 \%)$ & $10(35 \%)$ & $6(21 \%)$ \\
\hline
\end{tabular}

\section{Incidents and compensation claims}

Table 5 shows musculoskeletal incidents and workers compensation claims for the perioperative department compared to the rest of the hospital. Before the program, the odds of a musculoskeletal-related incident were four times higher in the perioperative department compared to the rest of the hospital (OR 4.1, 95\% Cl 1.6, 10.7). Following the program, these odds were reduced by a statistically significant 60 per cent (OR 0.4, 95\% Cl 0.1, 8.0, $p=<0.01$ ). Before the program, the odds of a compensation claim in the perioperative department were comparable to the rest of the hospital (OR 1.1, 95\% Cl 0.5, 2.3).
Following the program, the odds were reduced by 50 per cent (OR $0.5,95 \% \mathrm{Cl} 0.1,1.5, p=0.8$ ), but this did not reach the level of statistical significance.

\section{Acceptability, feasibility and program use}

Table 6 shows that more than 70 per cent of participants agreed 
or strongly agreed that the program was acceptable and feasible. There was over 85 per cent agreement that the program was a good fit for the department and matched its needs. When asked about anticipated use versus actual use, the majority of participants (46\%) wished to use the stretching station three times per week, but more than half (56\%) used it once a month or less.

\section{Qualitative feedback}

Ten participants were interviewed with each interview lasting approximately 30 minutes. The feedback was categorised into three themes which broadly described the positive attributes of the program, things that were thought to be drawbacks, and recommendations for implementation.

\section{Positive attributes}

Staff overwhelmingly felt that the program was beneficial for themselves and the others who used it. Several participants reported that the program improved an existing musculoskeletal disorder while others used it primarily as a means of preventing the occurrence of new injuries.

'The program is a good addition to my back-care routine, which I use to prevent injuries. I'm pretty new to nursing, and you hear all the stories about how it ruins your back, and if you don't look after yourself you pay for it in the long run' (P 10)

The interviews highlighted several unanticipated consequences of the program for staff and the department in general. Participants felt that the increased focus on staff health resulted in an overall 'boost to staff morale' which in turn resulted in an 'uplifting and positive culture in the unit'. One participant described the following:
'There's a new culture now. People will cover for your break so you can go and stretch and vice versa.' (P 5)

The program was also seen to raise the awareness of musculoskeletal injuries in perioperative staff.

'One of the best things about it [the program] is the attention it brought to the issue. It's okay to say that you're looking after your back. People are just a lot more aware.' (P 6)

The participants expressed surprise at the non-physical benefits of the program. The psychological downtime, mindfulness, relaxation and self-care aspects that arose from the program were highlighted as significant benefits, particularly in the high-stress environment of the perioperative department. One participant reported that:

'For me, just that ten minutes doing some slow stretching slows your thought process down, allowing you to consolidate. I like to stretch at the end of my day because that allows me to, sort of, delineate between work and home.' ( $p 4$ )

\section{Drawbacks}

The most common drawback reported by participants was not having enough opportunity to use the stretching station. Time management, the allocation of breaks, workload, relief staff and overall staffing challenges were the main issues raised.

'The only thing that has made it difficult is just getting the time to get there [to the stretching station]. There are a lot of different factors that come into that. But I guess staffing is the main one' (P 7)

One opportunity for improvement that participants identified related to the orientation of staff to the stretching station and stretching routine. Several participants felt that staff would feel more confident to use the stretching station if they had been shown how to perform the stretches by a physiotherapist.

'There's only the pictures [of the stretches], and sometimes pictures are hard to work out. I think that it would have been beneficial if somebody showed you how to do them the first time' (P 2)

\section{Recommendations for implementation}

It was acknowledged by participants that the stretching station needs to be in an optimal area that is easy to access but also provides users with privacy. There were mixed feelings among the participants as to whether the unused recovery bay provided enough privacy for users. Participants agreed that having the stretching station set up with the equipment ready to use saved time and maximised the opportunity for staff to stretch.

'We were lucky in having the ability to have a dedicated space. It was just always set up for us, so you never had to go and spend a couple of minutes getting the equipment out' (p 5)

For successful implementation, it was deemed essential to 'get everyone involved and let everyone have their input, so it becomes a department project'. Ensuring that staff can be involved was seen as critical for building engagement and fostering a feeling of ownership. Participants made it clear that implementation would not have been as successful if the staff had felt the program was being 'thrust upon them'. Along with a sense of shared ownership, it was suggested that there needs to be a 'core group of people to lead and drive' the implementation. 


\section{Discussion}

Workplace stretching programs have become increasingly popular in many industries for several reasons, including the ageing of the workforce, the escalating cost of workers compensation and insurance, and growing community intolerance of workplace-related injuries ${ }^{10}$. Previous studies of stretching programs for the prevention of musculoskeletal disorders have been conducted with surgeons but this is the first to focus more broadly on perioperative staff and the first to incorporate a qualitative component. Workplace stretching programs with surgeons have reported improvements in musculoskeletal discomfort, pain and overall general health ${ }^{6-8}$.

As the perioperative workforce ages, there is an increasing economic need for later retirement, for both individuals and organisations. Older health care workers are more prone to a range of chronic health conditions, including musculoskeletal disorders ${ }^{15,16}$. Given the need for our increasingly ageing workforce to remain healthy and productive, implementing effective injury mitigation practices such as workplace stretching programs would be prudent.

The participants in this study reported that they perform highrisk tasks - tasks associated with a risk of musculoskeletal injury for significant periods of the day. Approximately 20 per cent felt they spent more than half their day performing such tasks. A US study ${ }^{17}$ of perioperative nurses using the same ergonomic assessment tool reported a similar, albeit slightly higher amount, at 29 per cent. The most frequent high-risk tasks included standing static in one place, pushing or pulling objects, handling bulky objects at arm's length, carrying 5 to
$15 \mathrm{~kg}$, and carrying more than $5 \mathrm{~kg}$ with one hand.

Because of the nature and frequency of the tasks performed, musculoskeletal disorders are particularly common in perioperative staff $^{3,18}$. In this study, 88 per cent of participants had experienced musculoskeletal discomfort (aches and pain) in the last seven days. This finding is similar to studies of perioperative nurses in Switzerland ${ }^{19}$, the US ${ }^{17}$, and Greece ${ }^{18}$ who reported 88 per cent, 90 per cent, and 94 per cent, respectively. These findings support the need for programs such as workplace stretching to mitigate and rehabilitate work-related musculoskeletal disorders.

The qualitative feedback from this study provides some valuable insight into workplace stretching programs. Participants in this study reported positive effects on physical health as previously reported in the literature ${ }^{5,10}$ but they also described unanticipated benefits of the program on their psychological wellbeing and the overall workplace culture. These findings suggest that the mechanism of action of workplace stretching programs may be more complicated than first thought.

One feature of any successful workplace health and safety program is its perceived acceptability to the target group. Forty-two of the 85 staff in the perioperative department participated in the program, which indicates its broad appeal. When asked, more than 70 per cent felt that the program was acceptable and indicated they would continue using it if possible. The qualitative feedback revealed that an inclusive approach to the implementation helped build engagement and a sense of ownership which the participants felt was central to its success.

One barrier that was identified in the interviews was a lack of confidence to undertake the stretches. Participants received a brief orientation to the stretching station and static posters depicted the stretches but this was not seen as enough instruction to make some participants confident in their ability to effectively undertaking the stretches. Future efforts to implement workplace stretching into the perioperative environment could consider augmenting the instruction with a video demonstration that can be reviewed by the participants at any time.

In Australia, work-related musculoskeletal disorders are the leading work health and safety problem, costing almost \$24 billion annually? In this study, claims reduced from six in the previous year to zero in the year the program was implemented. On average, one musculoskeletal compensation claim costs approximately \$5500 (local data 2017-2018). The total saving from claims more than covers the $\$ 2,500$ program implementation cost. These implementation costs included medical-grade stretching equipment (stability ball, foam roller, mat) and approximately 24 work hours to manage the project and orientate staff to the stretching station.

\section{Limitations}

The acceptability and feasibility survey and the follow-up interviews were conducted with those staff who participated in the program. It would be beneficial in future studies to understand why people did not take up the program and what could be done to persuade them to do so in the future. 


\section{Conclusion}

The workplace stretching program had a positive impact on musculoskeletal disorders, sick leave, incidents and compensation claims. Participating staff felt the program was highly acceptable, feasible and a good fit for the department. Qualitative feedback highlighted unanticipated psychological and cultural benefits that had a positive impact on participating staff and the department overall. Given the positive results and the minimal resource requirements it is recommended that other departments consider implementing a similar program to complement existing work health and safety initiatives.

\section{Acknowledgements}

This study was funded by grants from the Mid North Coast Local Health District and the University of Newcastle Priority Research Centre for Health Behaviour. The authors would like to acknowledge the assistance of Luke Foley, senior physiotherapist, and Alison McQuaid, clinical nurse educator, from Port Macquarie Base Hospital.

\section{References}

1. Oakman J, Clune S, Stuckey R. Work-related musculoskeletal disorders in Australia, 2019. Canberra: Safe Work Australia; 2019.

2. Safe Work Australia. The cost of workrelated injury and illness for Australian employers, workers and the community: 2012-13. Canberra: Safe Work Australia; 2015.

3. Meijsen P, Knibbe HJ. Work-related musculoskeletal disorders of perioperative personnel in the Netherlands. AORN J 2007;86(2):193-208.

4. Hughes NL, Nelson A, Matz MW, Lloyd J. AORN Ergonomic tool 4: Solutions for prolonged standing in perioperative settings. AORN J 2011;93(6):767-774.

5. Sundstrup E, Seeberg KGV, Bengtsen $E$, Andersen LL. A systematic review of workplace interventions to rehabilitate musculoskeletal disorders among employees with physical demanding work. J Occup Rehabil 2020:1-25. doi: 10.1007/ s10926-020-09879-x.

6. Giagio S, Volpe G, Pillastrini P, Gasparre G, Frizziero A, Squizzato F. A preventive program for work-related musculoskeletal disorders among surgeons: Outcomes of a randomized controlled clinical trial. Ann Surg 2019;270(6):969-975.

7. Hallbeck M, Lowndes BR, Bingener J, Abdelrahman A, Yu D, Bartley A et al. The impact of intraoperative microbreaks with exercises on surgeons: A multi-center cohort study. Appl Ergon 2017;60:334-341.

8. Voss RK, Chiang Y-J, Cromwell KD, Urbauer DL, Lee JE, Cormier JN et al. Do no harm, except to ourselves? A survey of symptoms and injuries in oncologic surgeons and pilot study of an intraoperative ergonomic intervention. J Am Coll Surg 2017;224(1):16-25. e1.

9. Curran GM, Bauer M, Mittman B, Pyne JM, Stetler C. Effectiveness-implementation hybrid designs: Combining elements of clinical effectiveness and implementation research to enhance public health impact. Med Care 2012;50(3):217-226.

10. Gasibat Q, Simbak NB, Aziz A, Petridis L, Tróznai Z. Stretching exercises to prevent work-related musculoskeletal disorders: A review article. Am J Sport Sci Med 2017;5(2):27-37.
11. Mayo Clinic. A guide to basic stretches [Internet]. Phoenix AZ; Mayo Clinic; 2020 [updated Jan 2020; cited 2020 June]. Available from: www.mayoclinic.org/healthylifestyle/fitness/multimedia/stretching/ sls-20076840?s=6.

12. Hedge A. Cornell musculoskeletal discomfort questionnaires (CMDQ) [Internet] Ithaca NY: Cornell University Ergonomics; 1999 [cited 2020 June]. Available from: ergo.human.cornell.edu/ahmsquest.html.

13. Weiner BJ, Lewis CC, Stanick C, Powell BJ, Dorsey CN, Clary AS et al. Psychometric assessment of three newly developed implementation outcome measures. Implement Sci 2017;12(1):1-12.

14. Braun V, Clarke V. Using thematic analysis in psychology. Qual Res Psychol 2006;3(2):77101.

15. Heiden B, Weigl M, Angerer P, Müller A. Association of age and physical job demands with musculoskeletal disorders in nurses. Appl Ergon 2013;44(4):652-658.

16. Department of Health. Australia's future health workforce - nurses [Internet]. Canberra: Department of Health; 2015 [cited 2020 June]. Available from: www1.health.gov.au/internet/main/ publishing.nsf/Content/australias-futurehealth-workforce-nurses.

17. Sheikhzadeh A, Gore C, Zuckerman JD, Nordin M. Perioperating nurses and technicians' perceptions of ergonomic risk factors in the surgical environment. Appl Ergon 2009;40(5):833-839.

18. Bakola H, Zyga S, Stergioulas A, Kipreos G, Panoutsopoulos G eds. Musculoskeletal problems among Greek perioperative nurses in regional hospitals in Southern Peloponnese 2017. In: Vlamos P ed. GeNeDis 2016 Proceedings of the 2nd World Congress on Genetics, Geriatrics and Neurodegenerative Disease Research. Cham: Springer International Publishing; 2017, 21-37.

19. Nützi $M$, Koch $P$, Baur $H$, Elfering $A$. Workfamily conflict, task interruptions, and influence at work predict musculoskeletal pain in operating room nurses. Saf Health Work. 2015;6(4):329-337. 